\title{
COVID-19: Exploring Pilgrims' Travel Risks Perception
}

Ezwani Azmi, Mashita Abdul Jabar, Dayana Nor Azhar, Rina Syahirah Rosli \& Muhammad Nuruddin Zanki Armas

To Link this Article: http://dx.doi.org/10.6007/IJARBSS/v11-i10/10912 DOI:10.6007/IJARBSS/v11-i10/10912

Received: 02 August 2021, Revised: 30 August 2021, Accepted: 19 September 2021

Published Online: 01 October 2021

In-Text Citation: (Azmi et al., 2021)

To Cite this Article: Azmi, E., Jabar, M. A., Azhar, D. N., Rosli, R. S., \& Armas, M. N. Z. (2021). COVID-19:

Exploring Pilgrims' Travel Risks Perception. International Journal of Academic Research in Business and Social Sciences, 11(10), 93-107.

\section{Copyright: (c) 2021 The Author(s)}

Published by Human Resource Management Academic Research Society (www.hrmars.com)

This article is published under the Creative Commons Attribution (CC BY 4.0) license. Anyone may reproduce, distribute, translate and create derivative works of this article (for both commercial and non-commercial purposes), subject to full attribution to the original publication and authors. The full terms of this license may be seen

at: http://creativecommons.org/licences/by/4.0/legalcode

Vol. 11, No. 10, 2021, Pg. 93 - 107

Full Terms \& Conditions of access and use can be found at http://hrmars.com/index.php/pages/detail/publication-ethics 


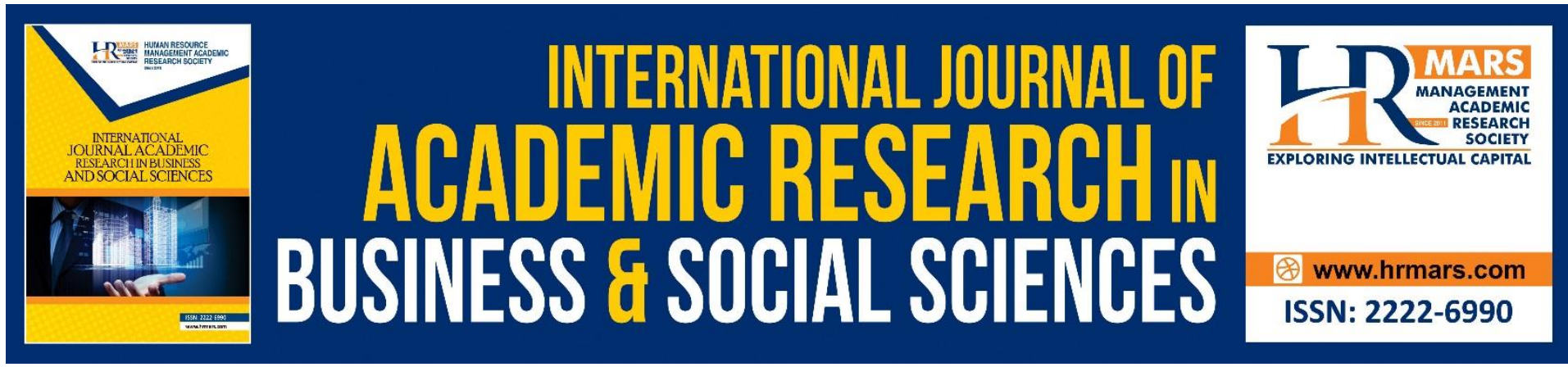

\title{
COVID-19: Exploring Pilgrims' Travel Risks Perception
}

\author{
Ezwani Azmi, Mashita Abdul Jabar, Dayana Nor Azhar, Rina \\ Syahirah Rosli \& Muhammad Nuruddin Zanki Armas \\ Faculty of Hotel and Tourism Management, Universiti Teknologi MARA, Cawangan Melaka, \\ Malaysia \\ Email: ezwaniazmi@gmail.com
}

\begin{abstract}
The outbreak of COVID-19 has placed the world in a crisis like no other, which has a significant impact on the lives of people and the travel industry. Due to the increasing number of COVID19 cases, this situation may also affect the pilgrims to travel for the annual Hajj and Umrah in mass gatherings as it can spread infectious diseases between pilgrims and the host community. Therefore, this study aims to determine the Hajj and Umrah pilgrimage's risk perception regarding the COVID-19 issues, which may contribute to the pilgrim's willingness to travel to Saudi Arabia after the pandemic ends. This study was conducted while COVID-19 cases were still high in Malaysia. The online survey was distributed to registered Umrah \& Hajj pilgrims, and they were selected based on simple random sampling. The results showed that as tourists perceive more risks during religious mass gatherings of Hajj and Umrah, their willingness to travel decreases. Overall, this study might contribute in providing pilgrimage data to tourism practitioners.
\end{abstract}

Keywords: COVID-19, Mass Gathering, Hajj, Umrah, Risk Perception, Travel Willingness

\section{Introduction}

Hajj is one of Islam's five pillars and an obligation for every capable Muslim to perform it only once in a lifetime in the month of Hajj, Zulhijjah (Hashem et al., 2019; Memish et al., 2014). On the other hand, Umrah means tawaf in Baitullah and Saie between Safa and Marwah when one is in the state of ihram where Umrah can be performed anytime throughout the year (Al-Tawfiq, Gautret \& Memish, 2017) with roughly 10 million pilgrims from 182 countries, the pilgrimage to Makkah, Saudi Arabia, is one of the world's greatest yearly mass religious gatherings (Memish et al., 2014). However, the recent COVID-19 pandemic poses a severe public health concern worldwide. The risk of infectious illnesses being exported to the pilgrims' home nation highlights the importance of planning, global communication, public health surveillance, and reaction during religious mass gatherings (Atique \& Itumalla, 2020).

In response to the COVID-19 spread, several nations from which a substantial number of Muslim pilgrims originate, including Malaysia, Indonesia, India, and Singapore, have now 
stated that their pilgrims would be unable to attend the 2020 Hajj (Zumla et al., 2020). As for Malaysia government normally send out thousands of people to the holy pilgrimage of Hajj in the Kingdom of Saudi Arabian. Malaysian Hajj Fund had reported 30,200 the official Hajj quota for Malaysian pilgrims every year (Algaissi et al., 2020). Recently, even more remarkable for Malaysian, the Minister in the Prime Minister's Department (Religious Affairs) had announced, Malaysia will not send pilgrims for the $1442 \mathrm{H}$ Hajj season after the Saudi government decides to allow only residents and nationals of the country to conduct the pilgrimage in 2021. Therefore, the number of haj pilgrims in 2021 is limited to only 60,000 people for residents of all nationalities and citizens inside Saudi Arabia (Malay Mail, 2021). As for the Saudi Arabian government, they have increased the 2021 Hajj Pilgrimage compared to 2020, which is limited to just 1,000 people living in the kingdom, consists of the worker pool, locals, healthcare professionals as well as security professionals, particularly individuals who have healed from COVID-19 (Al Jazeera, 2020).

Even though internationally, more than 1.4 billion vaccination doses have been delivered (Loo \& Letchumanan, 2021). Many countries are considering opening economic operations to restart socio-economic activities in response to the proposed vaccination program; almost one-third of Malaysians were still sceptical about the safety of COVID-19 vaccines. Malaysia vaccination program also has begun in the middle of the first quarter of 2021 (Wong, Juwono \& Chua, 2021). Therefore, this study aims to determine the risk perception of the potential Hajj and Umrah pilgrimages on COVID-19 issues among Malaysians and investigate travel willingness among the potential Hajj and Umrah pilgrimages. Despite the reality that Muslims need to perform Hajj once in their life to complete the five pillars of Islam, which is obligatory to perform it in the month of Hajj, Zulhijjah (Algaissi et al., 2020), does this pandemic impact the rest of the world make Malaysia still doubtful of their next journey?

\section{Travelling but 'haunted by COVID-19'?}

COVID-19 has harmed people's life not just in the health and economic spheres, but also in religious activities (Septoyadi, Lastriana, \& Muzammil). Three million people gathered in one place in Mecca, and with social distancing, it would be difficult to perform the worship. For example, during the Hajj, the Tawaf rite is performed at Makkah's Masjid Al-Haram, which has the most difficult crowd dynamics, with up to 7.5 passengers every 9.0 square feet, causing throughput, satisfaction, health, and safety concerns (Khan \& McLeod, 2012). Tawaf entails seven counter-clockwise circumambulations of the Kaaba, which can occur in the courtyard, second floor, or roof of Masjid Al-Haram, with each circuit beginning and ending at the Black Stone by touching or pointing to it (Khan \& McLeod, 2012). The largest mass gatherings in Saudi Arabia present significant effects during such a worldwide pandemic because millions of Muslims worldwide will go to Saudi Arabia to perform Umrah and Hajj (Shafi et al., 2008).

Mass gathering preparedness is a crucial matter, and it has been claimed that public health plays an essential strategic and technical role in keeping the people safe and healthy during large gatherings. If steps to properly plan and respond are not adopted, mass gatherings can raise the danger of health security, social anxiety, political urgency, and economic disruption (Ridda et al., 2019). Thus, the mass gathering is most likely raising social anxiety in public, especially those who need to go to Mecca to perform the worship. 
According to the studies by Singh, Tech, Gupta, \& Chakrabarty (2020) on post-COVID19 travel behaviour has been declared that people's mental health has suffered as a result of their dread of becoming infected, and this psychological stress has worsened since the lockdown. Since a result, psychological stress will influence travel behaviour, as people may experience worry and worry when using public transportation. Some may even have fear and anxiety to travel outside, especially if they had planned to perform Umrah Hajj after Covid-19 has recovered.

Therefore, the purpose of the study is to explore the extent to which Malaysians are willing to take risks to travel for Hajj and Umrah. According to Deng \& Ritchie (2018), risk is defined as the possibility of a loss of something of value or something bad happening at a point in the future. Meanwhile, perceived risk is a consumer's sense of ambiguity or negativity of an activity based on potential negative outcomes beyond one's acceptable threshold. The study has adopted a 'sensation seeking' conceptual framework by Sharifpour, Walters \& Ritchie (2013) to demonstrate risk perception among Umrah and Hajj pilgrims mass gathering since the COVID-19 pandemic.

Travel risk perception will influence tourists' willingness to travel, such as travellers willing to take risks when travelling with experience. Willingness to travel refers to the maximum distance that an individual is willing to travel under specific circumstances. For example, some tourists are willing to take the consequences of their decision to worship and attend a mass gathering in Saudi Arabia. Referring to the framework in Figure 1, three variables consist of psychological risk, physical risk, and travel-related risk. Therefore, travel risk perceptions may negatively or positively impact tourism risk perception of mass gatherings since the COVID-19 pandemic.

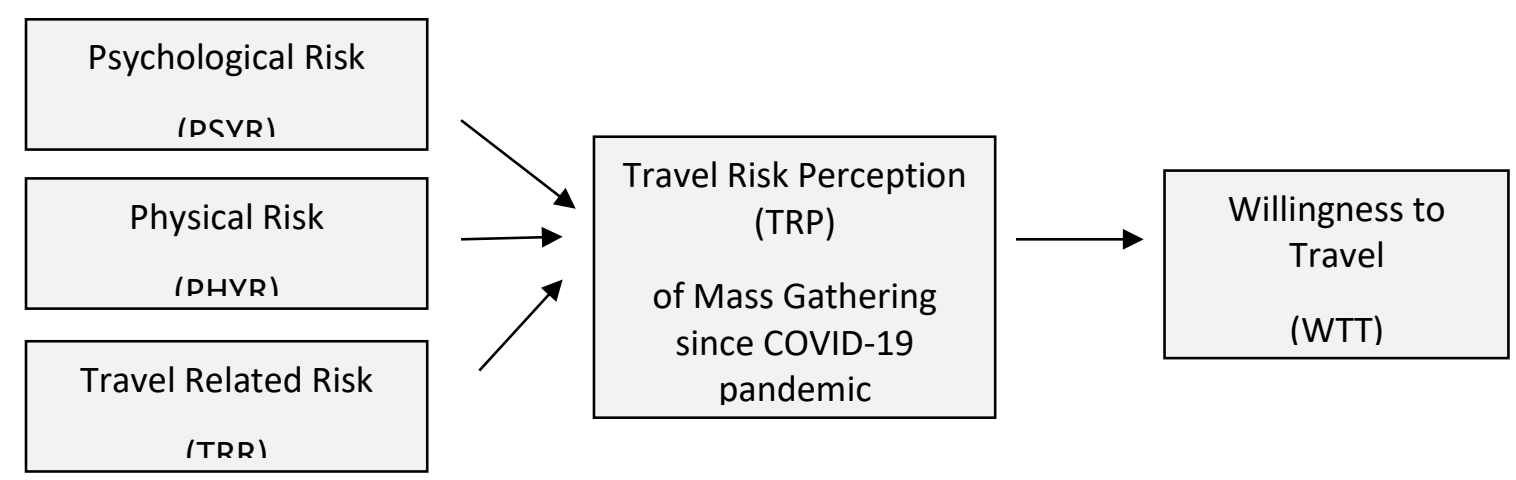

Figure 1. The Travel Risk Perception framework was adapted from "The Mediating Role of Sensation Seeking on The Relationship between Risk Perceptions and Travel Behaviour" by Sharifpour, Walters, \& Ritchie (2013). This measure will be based on the perception of travel risk to tourists. Based on the framework, four hypotheses were proposed as follows.

$\mathrm{H} 1$ : There is a significant association between PSYR and TRP

$\mathrm{H} 2$ : There is a significant association between PHYR and TRP

H3: There is a significant association between TRR and TRP

$\mathrm{H} 4$ : There is a significant association between TRP and WTT 


\section{Methodology}

A quantitative survey is used to explore three variables: psychological risk, physical risk, and travel-related risk related to the perception of mass gathering. Travel risk perception can be characterised as a post-acquiring assessment opinion regarding travel willingness. The questionnaire comprises two sections, sections $A$ and $B$, in which section $A$ discusses more on the respondent's demographic characteristics, and section $B$ is divided into three sections, i.e., risk perceptions, travel risk perception and willingness to travel. All respondents were asked to assign each of the questionnaires employing a 5-point Likert Scale ranging from strongly disagree (1) to strongly agree (5).

The source of secondary data or information was collected from various sources such as newspaper publication, journal articles, government official websites, and statistic data mainly. For example, Tabung Haji official website, Al Jazeera online news, World Health Organization official website, General Authority for Statistics of Saudi Arabia and many more. The secondary data sources are important as this COVID-19 issue is still rampant in the community. Therefore, it involves the data of the changes in the statistical number of pilgrims' arrival in Saudi Arabia, the new implementation of Standard Operating Procedures (SOP), and the Hajj restrictions to perform the ritual during the COVID-19 pandemic.

Simple Random Sampling was adopted whereby each item in the population has an equal probability and likelihood of being chosen for the sample. The sample population of this survey are Hajj and Umrah pilgrims and Muslims in Malaysia, aged 20 to 50 years old, who are expected to travel to Saudi Arabia for worship after the pandemic COVID-19 ends. The data collection approach that has been used in this study is quantitative by conducting an online survey in January 2021. Two methods were utilised to calculate the inverse square root approach and the gamma-exponential strategy for estimating the minimal sample size in PLSSEM (Kock and Hadaya, 2016). Using the inverse square root technique, the required sample size was 160, while the gamma-exponential method minimum required sample size was 146 respectively. As a result, for a PLS-SEM analysis, a sample size of 200 returned questionnaires was deemed acceptable for this study.

\section{Data Analysis Approach}

The data were subjected to various preliminary analyses before being used to test the measurement model's fitness and hypotheses. First, the programme, SPSS 23.0, was used to perform several analyses, including checking for missing values, outliers and testing for normality. The PLS estimation technique was then performed using WarpPLS 7.0 to test the hypotheses. PLS-SEM is a multivariate statistical technique that uses measurement and structural components to examine the connection between each variable in a conceptual model at the same time. This approach has been widely used in business and social science research to analyse route models with variables evaluated indirectly through other variables across various disciplines.

Structural equation modelling (SEM) enables complex model relationships to be examined simultaneously across numerous independent and dependent variables, as well as theories of moderation and mediation. A second-generation multivariate data analysis approach combines factor analysis with regression (Hair, Black, Babin \& Anderson, 2014; Bodoff and Ho, 2016). Covariance-based SEM (CB-SEM) and variance-based SEM (VBSEM) are 
the two most often used methods for SEM (VB-SEM). On the one hand, CBSEM emphasises the overall fit of the observed covariance matrix with the hypothesised covariance model. On the other hand, the main assumptions of CB-SEM include multivariate normality of data, a small sample size, reflecting constructs, and the need for a good theoretical understanding of the model created (Joreskog and Wold, 1982).

The variance-based SEM, also known as partial least square - structural equation modelling (PLS-SEM), on the other hand, uses partial least squares and factor-based methods to explain variation. Furthermore, unlike CB-SEM, PLS modelling measures both reflecting and formative measurement models simultaneously (Diamantopoulos and Winklhofer, 2001). To execute this work employed WarpPLS, a non-linear variance-based structural equation modelling programme, to perform PLS-SEM analysis on the generated model.

WarpPLS is a software that generates estimations of real composites and factors for SEM utilising both traditional and factor-based PLS methods (Kock, 2017). It is worth noting that PLS-SEM has many advantages that have been discussed in the literature, including the capacity to work with small sample numbers efficiently (Chin, 1998), having lack of requirement for normally distributed data (Hair et al., 2014), and the ability to easily incorporate formatively measured constructs (Hair et al., 2014; Sarstedt, Ringle, Smith, Reams $\&$ Hair, 2014). Since the study is exploratory and the data obtained is not normally distributed, the PLS-SEM method is utilised to analyse the data. To uncover concerns of common method variance (CMV). Harman's single-component analysis was used. The result showed that the factor was 34.83\% and was lower than 50\% (Aulakh and Gencturk, 2000); hence it is thought to be devoid of technique biases (Table 1$)$.

\section{Analysis}

\section{Assessment of the Measurement Model}

The evaluation of model parameters in the measurement model stage includes reliability tests utilising Cronbach's Alpha and composite reliability (Kock, 2013; Urbach \& Ahlemann, 2010), validity analyses based on extracted average variance (AVE), standardised factor loadings, and cross-loadings (Hair et al., 2014). To begin, confirmatory factor analysis (CFA) was performed to evaluate the item reliability, convergent validity, and discriminant validity of the assessment scales. As for convergent validity, all of the items loaded above the minimum cut off limit of 0.50 (Bigozzi, Yi, \& Philipps, 1991), as indicated in Table 2, present that internal consistency was attained. Furthermore, all of the composite reliability (CR) and Cronbach's Alpha values were more than the minimal cut off point of 0.6 (Hair et al., 2014), and all of the average variance extracted (AVE) values met the minimal threshold of 0.50 . (Hair et al. 2014). Next, discriminant validity is used to assess whether the instrument can distinguish between or among different concepts (Table3). Heterotrait-Monotrait (HTMT) is a new criterion to test discriminant validity. The HTMT threshold should be lower than 0.85 or 0.90, significantly smaller than 1 (Henseler, Ringle and Sarstedt, 2015). All results were marked lesser than 1 . Consequently, the measuring model was deemed good and sufficient proof in terms of reliability, convergent validity, and discriminant validity.

The possibility of incorrect results when employing SEM emphasises analysing lateral and vertical collinearity between components (Kock \& Lynn, 2012). Warppls 7.0 calculates full collinearity for all constructions, enabling the evaluation of vertical and lateral collinearity 
between constructions simultaneously (Kock, 2013). Table 2 shows that the total collinearity of the constructs was less than 10 (Hair et al., 2014), which according to Kock (2015), is an acceptable collinearity criterion for factor-based PLS-SEM.

Table 1. Total Variance Explained.

Initial Eigenvalues

Extraction Sums of Squared Loadings

\begin{tabular}{lllllll}
$\begin{array}{l}\text { Component } \\
\text { Cumulative\% }\end{array}$ & Total & \multicolumn{2}{l}{$\%$ of Variance Cumulative \% Total $\%$} & of & Variance \\
\hline 1 & 5.572 & 34.825 & 34.825 & 5.572 & 34.825 & 34.825 \\
2 & 2.340 & 14.624 & 49.449 & & & \\
3 & 1.512 & 9.452 & 58.901 & & & \\
4 & .921 & 5.758 & 64.658 & & & \\
5 & .791 & 4.942 & 69.601 & & \\
6 & .715 & 4.468 & 74.068 & & \\
7 & .643 & 4.017 & 78.085 & & \\
8 & .600 & 3.749 & 81.834 & & \\
9 & .531 & 3.317 & 85.151 & & \\
10 & .465 & 2.908 & 88.060 & & \\
11 & .428 & 2.672 & 90.732 & & \\
12 & .416 & 2.602 & 93.334 & & \\
13 & .335 & 2.091 & 95.425 & & & \\
14 & .277 & 1.731 & 97.156 & & & \\
15 & .269 & 1.683 & 98.839 & & & \\
16 & .186 & 1.161 & 100.000 & & & \\
\hline
\end{tabular}

Extraction Method: Principal Component Analysis. 
Table 2. Assessment Results of the Measurement Model.

\begin{tabular}{|c|c|c|c|c|c|c|}
\hline Construct & Items & Loadings & $\begin{array}{l}\text { Cronbach's } \\
\text { Alpha }\end{array}$ & $C R$ & AVE & $\begin{array}{l}\text { Full collinearity } \\
\text { VIFs }\end{array}$ \\
\hline $\begin{array}{l}\text { Psychological } \\
\text { Risks } \\
\text { (PSYR) }\end{array}$ & $\begin{array}{l}\text { PSYR1 } \\
\text { PSYR2 } \\
\text { PSYR3 }\end{array}$ & $\begin{array}{l}0.823 \\
0.885 \\
0.836\end{array}$ & 0.804 & 0.885 & 0.719 & 2.195 \\
\hline $\begin{array}{l}\text { Physical Risks } \\
\text { (PHYR) }\end{array}$ & $\begin{array}{l}\text { PHYR1 } \\
\text { PHYR2 } \\
\text { PHYR3 }\end{array}$ & $\begin{array}{l}0.813 \\
0.753 \\
0.836\end{array}$ & 0.720 & 0.843 & 0.642 & 1.175 \\
\hline $\begin{array}{l}\text { Travel } \\
\text { Related Risks } \\
\text { (TRR) }\end{array}$ & $\begin{array}{l}\text { TRR1 } \\
\text { TRR2 } \\
\text { TRR3 }\end{array}$ & $\begin{array}{l}0.748 \\
0.765 \\
0.796\end{array}$ & 0.657 & 0.814 & 0.593 & 1.860 \\
\hline $\begin{array}{l}\text { Travel Risk } \\
\text { Perception } \\
\text { (TRP) }\end{array}$ & $\begin{array}{l}\text { TRP1 } \\
\text { TRP2 } \\
\text { TRP3 } \\
\text { TRP4 }\end{array}$ & $\begin{array}{l}0.817 \\
0.883 \\
0.845 \\
0.820\end{array}$ & 0.862 & 0.907 & 0.709 & 2.213 \\
\hline $\begin{array}{l}\text { Willingness } \\
\text { To Travel } \\
\text { (WTT) }\end{array}$ & $\begin{array}{l}\text { WTT1 } \\
\text { WTT2 } \\
\text { WTT3 }\end{array}$ & $\begin{array}{l}0.726 \\
0.834 \\
0.879\end{array}$ & 0.745 & 0.855 & 0.665 & 1.093 \\
\hline
\end{tabular}

Table 3. Discriminant validity of constructs (HTMT Ratios).

\begin{tabular}{lrrrrr}
\hline \multicolumn{1}{c}{ PSYR } & PHYR & TRR & TRP & WTT \\
\hline PSYR & & & & & \\
PHYR & 0.377 & & & & \\
TRR & 0.827 & 0.441 & & & \\
TRP & 0.824 & 0.215 & 0.821 & & \\
WTT & 0.299 & 0.267 & 0.219 & 0.277 & \\
\hline
\end{tabular}

\section{Assessment of the Structural Model}

The purpose of assessing structural models is to examine whether the model can predict one or more target constructs. Table 4 shows the goodness of fit of the structural model, and it indicates a good fit. Two preliminary criteria should be evaluated and reported when evaluating the structural model, i.e., the relevance of the track coefficients and the value of the R2 coefficient for endogenous constructs. R2 values of $0.67,0.33$, and 0.19 are considered considerable, moderate, and weak, respectively (Chin, 1998). As a result, the $R^{2}$ for Travel Risk Perception was 0.58, which is regarded above moderate, while $R^{2}$ for Willingness to Travel was 0.06 and is considered weak or low (Figure 1). As a result, the R2 
values in this study showed that, while the proportion of variance in Travel Risks Perception is well explained, other missing factors are likely to account for a substantial portion of the variance in Willingness to Travel.

Table 4. The goodness of fit in the structural model.

\begin{tabular}{lll}
\hline Index & Index value in the model & Allowed value \\
\hline Average path coefficient (APC) & 0.292 & $<=0.05$ \\
Average R squared (ARS) & 0.319 & $<=0.05$ \\
Average (AVIF) & 1.456 & $<=5$ \\
Sympson's paradox ratio (SPR) & 1 & $>=0.7$ \\
Statistical suppression ratio (SSR) & 1 & $>=0.7$ \\
\hline
\end{tabular}

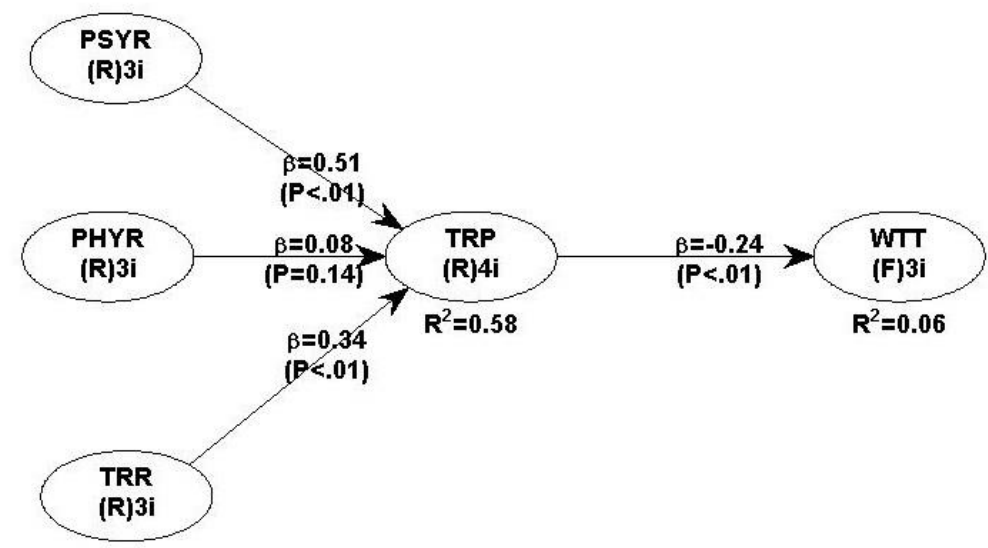

Figure 1. Research model with path coefficient and p-values.

The outcomes of the hypothesis and the evaluation of path coefficients are shown in Table 5 and Figure 1. The results reveal that PSYR has a favourable and substantial influence on TRP (H1), but PHYR has a non-significant effect on TRP (H2). On the other hand, TRR was shown to have a positive and substantial influence on TRP (H3). Meanwhile, the effect of TRP on WTT $(\mathrm{H} 4)$ showed a negative relationship yet significant.

Table 5. Results of hypothesis testing

\begin{tabular}{|l|l|l|l|l|}
\hline & Hypothesis & Path coefficient & $p$-value & Supported \\
\hline H1 & PSYR $\rightarrow$ TRP & 0.51 & $<0.01$ & Yes \\
\hline H2 & PHYR $\rightarrow$ TRP & 0.08 & 0.14 & No \\
\hline H3 & TRR $\rightarrow$ TRP & 0.34 & $<0.01$ & Yes \\
\hline H4 & TRP $\rightarrow$ WTT & -0.24 & $<0.01$ & Yes \\
\hline
\end{tabular}

$\mathrm{H} 1$ : There is a positive and significant relationship between PSYR and TRP

$\mathrm{H} 2$ : There is a non-significant relationship between PHYR and TRP

H3: There is a positive and significant relationship between TRR and TRP

$\mathrm{H} 4$ : There is a negative yet significant relationship between TRP and WTT

\section{Discussion and Conclusion}

'There is a positive and significant relationship between PSYR and TRP'. Referring to the analysis, psychological risk had influenced and affected Hajj, and Umrah pilgrims travel risk perception. The result shows that psychologically respondents are still thinking about the 
risk of travelling to Saudi Arabia to perform Hajj and Umrah since the COVID-19 pandemic. It was observed that the respondents are anxious about travelling as they think that travelling would give them a serious negative impact on their travel experience. Psychological risk relates to the potential adverse impact of travel experiences on the characteristics or personality of the traveller (An, Lee, \& Noh, 2010). Some might have a mindset to perceive that the destination is not safe, and they will tend not to travel to the destination. For example, due to COVID-19, pilgrims will start thinking about whether to continue planning or not to perform Umrah or Hajj soon. Other than that, respondents were also questioned concerning the opinions of family and relatives about the place they would visit. The results show the views and concerns of close people such as family, which have influenced the respondents' decisions to visit Saudi Arabia. This is not unusual as this includes studies conducted by Sönmez \& Graefe (1998) in Europe, where it has also been agreed that friends or relatives also disapproved of one's travel choice, which was a significant indicator to travel.

However, there is a non-significant relationship between physical risk and the travelrelated perception as proposed in Hypotheses 2; 'There is a non-significant relationship between PHYR and TRP'. It shows that major respondents are fully aware and well prepared for physical activities while travelling. By individual statement, the pilgrims strongly agreed and are willing to take precautions related to physical activities. Respondents are aware and well prepared by always practising 3Ws (Wash, Wear \& Warn) and avoid 3Cs (Crowded places, Confined spaces, \& Close conversation) to avoid high risk to get infected during Hajj pilgrimage. Preparations like medicines, vaccinations, maintaining personal hygiene and using hand sanitiser may prevent them from experiencing COVID-19. Although An, Lee, \& Noh (2010) identified that the probability of physical harm during travel would involve physical danger, most of the respondents were prepared to take such measures. Despite the pandemic, precautions have already been applied and become a person's daily practice in this new norm. This was also acknowledged by Bae \& Chang (2021), where Koreans have grown extremely worried among Koreans when it comes to COVID-19, not because of the disease's potential medical consequences but because of other factors such as social isolation. The people's unease can be seen with the current situation of the third movement order control of Malaysians, which has dragged on self-isolation for more than a month from June until now July 2021 is still rising to 13,000 positive cases every day. However, in Korea, the key driver in Korean culture keeping the degree of widespread infection low throughout the pandemic is the people's strict adherence to preventive behaviours such as mask-wearing and social distancing. In other words, the physical risk does not influence the perceptions of travel risk among respondents.

Meanwhile, the result positively confirmed that travel-related risk affected pilgrims' perception to travel Saudi Arabia for Hajj and Umrah as suggested in Hypotheses 3; 'There is a positive and significant relationship between TRR and TRP'. Respondents are very concerned about the new Standard of Procedures (SOPs), and policies, worries of additional travel expenses, high financial commitment than before and travel durations since new policies will be involved after the occurrence of the pandemic. Awad-Núñez et al (2021) explored the issues of people's 'willingness to pay in the field of transportation, and as we know, the effects of pandemic involve crowding reduction, safety and facilities improvements as well. Other than the money issue, Matiza (2020) insisted that governments must catalyse destination marketing and promotion by undertaking public diplomacy initiatives aimed at establishing 
and controlling international communication channels, restoring tourist trust, and repairing destination image as well as stimulus packages. Other travel preparation factors also affected people's decision to a destination, explicitly cost, the destination's image, and new rules that need to be followed.

Therefore, travel risk perception in this study had been formed from several variables; psychological risk, physical risk, and travel-related risk, which are the important indicators for a first-time pilgrimage or a repeated pilgrimage willingness to travel during the pandemic. As proposed in Hypotheses 4; 'There is a negative yet significant relationship between TRP and WTT'. In other words, the study confirmed that as tourists perceive more risks during the religious mass gathering of Hajj and Umrah, it will decrease the willingness of tourists to travel. Respondents are concerned and aware of the risk that they might face. The majority of the respondents agreed that prolong exposure in public, especially during mass gatherings, might be affected by potential infectious COVID-19. The result shows that the travel risk perception of the pilgrims may affect their willingness to travel since the COVID-19 pandemic.

In a nutshell, from the three potential risks studied, PSYR, PHYR and TRR, only PHYR appeared to have a non-significant relationship with travel risk perception. On the other hand, PSYR and PHYR seemed positive and showed a significant relationship with travel perception. Overall, the variables reflected the analysis between TRP and indicated a negative yet significant relationship with WTT.

Nevertheless, Hajj and Umrah are compulsory for every Muslim worldwide who visited Saudi Arabia to perform worship. It is a destination dreamed by Muslims to achieve their self -actualisation, and it is also perceived as the need for novelty and eagerness. Although Sharifpour \& Walters (2014) opined that risk perception and safety are having a crucial impact on the remainder of the decision-making, the perceived risk can influence the behaviour of searching information, evaluating locations and results of travel decisions. However, undeniably, a final decision to travel might also be affected by other factors: media coverage, travel advisories, or social interaction.

From the study, the customers, practitioners, the authorities and those managing the pilgrims can take the initiative of concern over the risks that have been studied. This study makes several hypothetical contributions; first, it has incorporated tourist knowledge into the risks they will face before deciding to travel. Second, it has discovered and identified a gap in earlier research that requires more investigation. Third, this research has proposed extending travel risk perception with travel willingness, especially during this COVID-19 pandemic for Hajj and Umrah, filling the gap between TRP and WTT and looking from the point of view of mass gathering. Fourth, although there are obvious correlations between aspects of travel risk perception and willingness to travel, an empirical study is required to establish the relevance of each relationship and how it interacts with other variables in the model. Significantly, this study perhaps will help the government, especially the tourism sector and travel agencies that offer Hajj and Umrah packages, to formulate suitable strategies for the potential pilgrims to prepare to perceive risks that affect the pilgrims' willingness to travel due to the post-pandemic outbreak. Furthermore, the analysis will help tour operators or tourism players prepare to provide or make a tour package for performing Hajj and Umrah while considering the travel behaviour and the psychological factors that may arise among 
tourists. This action is crucial for the tourists or the consumers to consider in buying the package as it involves their safety and health both mentally and physically.

\section{Conclusion}

Even now, Malaysia and the Kingdom of Saudi Arabia never neglect and took the best solutions based on current situations. This ongoing pandemic has certainly caused strict procedures and regulations. In addition, more financial implications will be involved due to the number of pilgrims that will be reduced to maintain a social distance, finances in taking vaccines and medicines. New norms during pandemics have indirectly taught teach people to be more disciplined, have the awareness in avoiding crowded places, and keep the social distance and not forgetting, adhering to the rules. Furthermore, the limited numbers of pilgrims, movements and activities during Hajj and Umrah has been controlled since last year (2020). It is also deemed a bad sign for baby boomers and elders who are easily affected by the disease and may have higher chances of being badly affected by COVID-19. Most likely, the age factor will be an obstacle for pilgrims to perform Hajj and Umrah in future; even Hajj has always been known to be common among elders who find need to perform once in their lifetime.

\section{Recommendations}

The study confirmed that the pilgrim tourists are still thinking and anxious about traveling to do umrah and hajj which reflected their psychological risks affect travel risks perception. The roles of the media are very important at this stage whether the news released and disseminated is positive to increase public confidence or vice versa. People will build confidence through current case statistics as well as case studies for pilgrims who have completed their umrah after the onset of the COVID-19 season.

It was clear that umrah and hajj pilgrims do not worried about physical risks while traveling since they affirmed strict adherence to $3 \mathrm{Ws}$. The pilgrims perceived physical risks as not crucial as part of travel risks. However, the government still needs to limit the number of pilgrims, provide health assistance services, provide appropriate health application services for pilgrims who are in the 'Holy Land' as well as more detailed agency advisory services before and during performing Hajj and Umrah.

Apart from that, the pilgrims showed concern over travel related risks such as SOPs, policies, and additional travel expenses indicated that travel related risks did affect pilgrims' perception of travel risks. Relevant parties such as the government and travel agencies need to survey and consider the ability of the community so that the opportunity to perform Umrah and Hajj is not only for high-income groups. A variety of prices still needs to be offered to avoid discrimination and injustice despite the tightening of policies and conditions.

In the era of globalization, 'world without borders', it is easy for people to travel, despite the occurrence of pandemics, people will begin to adapt to the current atmosphere and conditions. The risk will be reduced with the enforcement of vaccines, aid, and health facilities, 'untact'. Untact refers to consumer behavior that avoids face-to-face interaction (Bae, 2021) for example machines and applications of technology reduce communication directly with humans, and indirectly reduce the rate of infection. 


\section{References}

Ahmed, Q. A., \& Memish, Z. A. (2020). The cancellation of mass gatherings (MGs)? Decision making in the time of COVID-19. Travel medicine and infectious disease, 34, 101631.

Algaissi, A., Alharbi, N., Hassanain, M., \& Hashem, A. (2020). Preparedness and response to COVID-19 in Saudi Arabia: Building on MERS experience. Journal of Infection and Public Health, 13(6), pp.834-838. doi.org/10.1016/j.jiph.2020.04.016

Al-Tawfiq, J. A., Gautret, P., \& Memish, Z. A. (2017). Expected immunizations and health protection for Hajj and Umrah 2018-An overview. Travel medicine and infectious disease, 19, 2-7. doi.org/10.1016/j.tmaid.2017.10.005

An, M., Lee, C., \& Noh, Y. (2010). Risk factors at the travel destination: their impact on air travel satisfaction and repurchase intention. Service Business, 4(2), 155-166.

Atique, S., \& Itumalla, R. (2020). Hajj in the time of COVID-19. Infection, disease \& health, 25(3), pp.219-221. https://doi.org/10.1016/j.idh.2020.04.001

Aulakh, P. S., \& Gencturk, E. F. (2000). International Principal-Agent Relationships. Industrial Marketing Management, 29(6), 521-538.

Awad-Núñez, S., Julio, R., Gomez, J., Moya-Gómez, B., \& González, J. S. (2021). Post-COVID19 travel behaviour patterns: impact on the willingness to pay of users of public transport and shared mobility services in Spain. European Transport Research Review, 13(1), 1-18.

Bae, S. Y., \& Chang, P. J. (2021). The effect of coronavirus disease-19 (COVID-19) risk perception on behavioural intention towards 'untact' tourism in South Korea during the first wave of the pandemic (March 2020). Current Issues in Tourism, 24(7), 10171035.

Bagozzi, R. R., Yi, Y., \& Philipps, L. W. (1991), Assessing construct validity in organizational research, Administrative Science Quarterly, Vol. 36 No. 3, pp. 421- 458.

Bodoff, D., \& Ho, S. Y. (2016). Partial least squares structural equation modelling approach for analyzing a model with a binary indicator as an endogenous variable.

Communications of the Association for Information Systems, 38, pppp. https://doi.org/10.17705/1CAIS.03823

Chen, C. C. (2020). Psychological tolls of COVID-19 on industry employees. Annals of Tourism Research.

Chin, W. (1998). The partial least squares approach for structural equation modeling. In G. Marcoulides (Ed.), Modern methods for business research (pp. 295336). Mahwah, NJ: Lawrence Erlbaum Associates

Deng, R., \& Ritchie, B. W. (2018). International university students' travel risk perceptions: an exploratory study. Current Issues in Tourism, 21(4), 455-476.

Diamantopoulos, A., \& Winklhofer, H. M. (2001). Index construction with formative indicators: An alternative to scale development. Journal of Marketing Research, 38(2), 269-277.

Fornell, C. G., \& Larcker, D. F. (1981), "Evaluating structural equation models with unobservable variables andmeasurement error", Journal of Marketing Research, Vol. 18 No. 1, pp. 39-50.

Hair, J. F., Black, W. C., Babin, B. J., and Anderson, R. E. (2014) Multivariate Data Analysis. $7^{\text {th }}$ Edition, Pearson, New York.

Hashem, A. M., Al-Subhi, T. L., Badroon, N. A., Hassan, A. M., Bajrai, L. H. M., Banassir, T. M. \& Azhar, E. I. (2019). MERS-CoV, influenza and other respiratory viruses among 
symptomatic pilgrims during 2014 Hajj season. Journal of medical virology, 91(6), 911917. https://doi.org/10.1002/jmv.25424

Jöreskog, K. G., \& Wold, H. O. A. (1982). The ML and PLS techniques for modeling with latent variables: Historical and comparative aspects. In H. O. A. Wold \& K. G. Jöreskog (Eds.), Systems under indirect observation, part I (pp. 263-270). Amsterdam: North-Holland.

Khan, I., \& McLeod, R. D. (2012). Managing hajj crowd complexity: Superior throughput, satisfaction, health, and safety. Kuwait Chapter of Arabian Journal of Business and Management Review, 33(853), 1-15.

Kock, N. (2017). Factor-based SEM building on consistent PLS: An information systems illustration. Laredo, TX: ScriptWarp Systems: Laredo, Texas, 1-28.

Kock, N., \& Hadaya, P. (2016), "Minimum sample size estimation in PLS-SEM: the inverse square root and gamma-exponential methods", Information Systems Journal, Vol.28No. 1, pp. 227-261

Kock, N. (2015). A note on how to conduct a factor-based PLS-SEM analysis. International Journal of E-Collaboration, 11(3), 19

Kock, N. (2013). WarpPLS 4.0 user manual. Laredo, TX: ScriptWarp Systems.

Kock, N., \& Lynn, G. (2012). Lateral collinearity and misleading results in variance-based SEM: An illustration and recommendations. Journal of the Association for Information Systems, 13(7), 546580.

Loo, K. Y., \& Letchumanan, V. (2021). COVID-19: Malaysia's fight against this deadly virus. Progress In Microbes \& Molecular Biology, 4(1).

Malay mail. (2021). Religious affairs minister: Malaysia not sending Haj pilgrims this year due to Covid-19. https://www.malaymail.com/news/malaysia/2021/06/12/religiousaffairs-minister-malaysia-not-sending-haj-pilgrims-this-year-due/1981741

Matiza, T. (2020). Post-COVID-19 crisis travel behaviour: towards mitigating the effects of perceived risk. Journal of Tourism Futures.

Memish, Z. A., Zumla, A., Alhakeem, R. F., Assiri, A., Turkestani, A., Al Harby, K. D., \& McCloskey, B. (2014). Hajj: infectious disease surveillance and control. The Lancet, 383(9934), 2073-2082. https://doi.org/10.1016/S0140-6736(14)60381-0

Qiu, R. T., Park, J., Li, S., \& Song, H. (2020). Social costs of tourism during the COVID-19 pandemic. Annals of Tourism Research, 84, 102994.

Ridda, I., Mansoor, S., Briggs, R., Gishe, J., \& Aatmn, D. (2019). Preparedness for mass gathering during Hajj and Umrah. Handbook of Healthcare in the Arab World, 1-21. https://doi.org/10.1007/978-3-319-74365-3_48-1

Sarstedt, M., Ringle, C. M., Smith, D., Reams, R., \& Hair, J. F. (2014). Partial least squares structural equation modeling (PLS-SEM): A useful tool for family business researchers. Journal of Family Business Strategy, 5(1), 105-115.

Shafi, S., Booy, R., Haworth, E., Rashid, H., \& Memish, Z. A. (2008). Hajj: health lessons for mass gatherings. Journal of infection and public health, 1(1), 27-32. https://doi.org/10.1016/j.jiph.2008.08.008

Sharifpour, M., \& Walters, G. (2014). The interplay between prior knowledge, perceived risk and the tourism consumer decision process: A conceptual framework. The Marketing Review, 14(3), 279-296.

Sharifpour, M., Walters, G., \& Ritchie, B. W. (2013). The mediating role of sensation seeking on the relationship between risk perceptions and travel behavior. Tourism Analysis, 18(5), 543-557. 
Singh, V., Tech, M., Gupta, K., \& Chakrabarty, N. (2020). Psychological Impacts on the Travel Behavior Post-COVID-19. Indian Institute of Technology Roorkee: Uttarakhand, India.

Sönmez, S. F., \& Graefe, A. R. (1998). Determining future travel behavior from past travel experience and perceptions of risk and safety. Journal of travel research, 37(2), 171177.

Wong, W. K., Juwono, F. H., \& Chua, T. H. (2021). Sir simulation of covid-19 pandemic in malaysia: Will the vaccination program be effective? arXiv preprint arXiv:2101.07494.

Zumla, A., Azhar, E., Alqahtani, S., Shafi, S., \& Memish, Z. (2020). COVID-19 and the scaled-down 2020 Hajj Pilgrimage-Decisive, logical and prudent decision making by Saudi authorities overcomes pre-Hajj public health concerns. International Journal of Infectious Diseases, 99, pp.34-36. https://doi.org/10.1016/j.ijid.2020.08.006 